\title{
THE INFLUENCE OF MOISTURE CONTENT ON THE ACOUSTIC EMISSION AT THRESHOLD OF ROCK DESTRUCTION
}

\author{
Qiang SUN ${ }^{1,3)}$ *, Ming JI ${ }^{1,2)}$, Lei XUE ${ }^{3)}$ and Tianming SU ${ }^{4)}$ \\ ${ }^{1)}$ School of Resources and Earth Science, China university of Mining and Technology, Xuzhou,221116, P. R. China \\ ${ }^{2)}$ School of Mines, China university of Mining and Technology, Xuzhou,221116, P. R. China \\ ${ }^{3)}$ Key Laboratory of Shale Gas and Geoengineering, Institute of Geology and Geophysics, Chinese Academy of Sciences, \\ Beijing 100029, P. R. China; \\ 4) Research Institute of Highway Ministry of Transport, Beijing 100088, China, P. R. China
}

*Corresponding author's e-mail: sunqiang04@126.com

\begin{tabular}{l} 
ARTICLE INFO \\
\hline Article history: \\
Received 6 November 2014 \\
Accepted 21 May 2015 \\
Available online 13 July 2015 \\
\hline
\end{tabular}

Keywords:

Acoustic emission

Peak strength

Moisture content

Process of destruction

Stress-strain

\section{ABSTRACT}

Investigations of rocks with different moisture contents demonstrate that during the process of failure, the number of acoustic emissions (AE) increases in the vicinity of the yield point with the rapid generation and growth of micro cracks. The increase of moisture content leads to decreased rock strength and fewer events of $\mathrm{AE}$, which suggests that the inner structure and mechanical properties of the rocks are changed. Moreover, less energy is released during the process of destruction, which exhibits little influence on the stress level at the threshold point of yield. One could use the variation of rock $\mathrm{AE}$ to obtain the end stress of rock elastic stage and Poisson's ratio. And the stress ratio at the critical point could be described by mathematical expressions.

\section{INTRODUCTION}

Rock mass in the crust usually exists in a state with changing moisture content and natural stress. Mining activities could change the stress distribution in the rock mass and create local stress concentration, leading to deformation and destruction depending on the structural characteristics and extraction condition (Cai et al., 1998; Butt et al., 2000). Therefore, rapid and effective detection of the inner state and mechanical characteristics of rocks is desired.

Many technical problems need to be solved in order to fully understand the rock failure process (Sun and Zhu, 2014), such as accurately determining the Poisson's ratio and identifying rock yield point. Additionally, the evolution of cracks with macro deformation and failure is not well understood. The acoustic emission (AE) occurred during destruction provides a way to learn more, as the variation of $\mathrm{AE}$ is closely related to rock failure process (Brace et al., 1966; Rudajev et al., 1996; Yang et al., 2003; Kramadibrata et al., 2011; $\mathrm{Xu}, 2012$ ). Hence, the variation of $\mathrm{AE}$ parameters may provide information about rock failure and could be used to predict seismic and geological disasters. Several research groups have studied the roles of $\mathrm{AE}$ in the prediction of rock failure. For example, Holcomb (1993) and Lavrov (2003) summarized and analyzed the relationship between the Kaiser effect and rock failure. Fonseka et al. (1985), Lockner et al. (1992), Martin and Chandler (1994), Cai et al. (2004), Dai et al. (2005) and Ganne et al. (2007) investigated the relationship between the microscopic breaking characteristics preceding brittle destruction and the AE, while Tan et al. (2000) proposed four precursor modes contained in the AE generated by pressure bumps. In addition, Pan and Yang (2004) pointed out that the frequency and energy of AE in coal mass change abruptly around its dilation point (i.e. yield point) and Li et al. (2004) showed that quasi-tranquility exists preceding the arrival of peak intensity of AE. Lamagnère et al. (1996), and Sornette and Andersen (1998) pointed out there is a critical region in the vicinity of the critical point of rupture, where variations in free energy, reflected in energy release, can be characterized by a power law with log-periodic oscillations (Sornette, 1988).

However, little is known about the influence of moisture content on the AE. It is reported that the strength of rocks would decrease greatly with the increase of moisture content. Therefore, characteristics of the acoustic emission generated by rocks with different moisture content are important to theoretical investigations and engineering applications. This paper investigates the stress and strain at the yield point and the peak stress point during the destruction of rocks with different moisture contents, and their relationship with the accompanying $\mathrm{AE}$ signals. The sharp increase of AE in the vicinity of the threshold stress point preceding failure is explained in the view of stress level. 


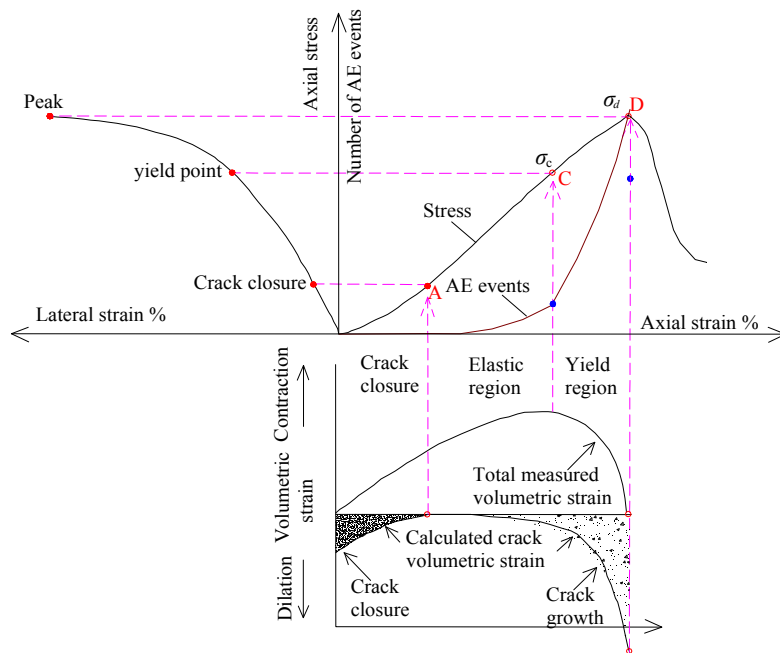

Fig. 1 The relationship between the parameters of rock stress, strain, and AE (after Martin et al. (2001) and Cai et al. (2004)).

\section{GEOMETRICAL FEATURES OF THE AE CURVE DURING LOADING PROCESS}

Based on the curves of (1) AE level vs. strain level, (2) stress level vs. strain level, and (3) stress level vs. time in Figure 1 obtained from experiments on rock samples with different moisture contents, the variation of AE with strain level can be separated into 3 phases (after Martin et al., 2001; Cai et al., 2004). (Fig. 1; The strain and stress level are normalized strain and stress relative to their peak values respectively, and the $\mathrm{AE}$ level refers to the accumulated number of events of AE (accumulated number of bell ringing) normalized by the final accumulated number of events at the completion of the experiment).

1. The compaction and elastic phase O-A-C (shown in Fig. 1). Initially, the axial deformation is dominantly linear, and rock deformation is mostly compaction, with negligible level of AE. The original micro fissures and pores are closed.

2. The yielding phase CD. Plenty of micro cracks initiate and grow rapidly, and micro breaking is developed spatially in rows along the potential breaking planes until the micro cracks eventually become connected with each other, as indicated by the localization of strain, nonlinear axial deformation, and accelerated increase of volumetric strain at the cracks. In this phase, the AE signal and the number of events increase sharply, with a jump in the vicinity of the yield point. This is shown as a steep change of slope in the accumulation curve and a sharp increase in the magnitude of the spectra of the acoustic signal.

3. Posterior peak phase DE. The loading capability of the rocks decreases rapidly, in transition from continuous and homogenous deformation to localized deformation. With the development of inner micro cracks into interconnected plane structure, the accumulated AE signals have almost reached the peak value, although this peak falls behind the peak stress in time.

Based on the above analysis, the yield point is defined as the point $\mathrm{C}$ corresponding to abrupt increase of the magnitude of emitted acoustic signal and the number of AE events (Martin et al., 2001; Cai et al., 2004). The stress and strain corresponding to the point $\mathrm{C}$ and $\mathrm{D}$ are represented as $\left(\sigma_{c}, \varepsilon_{c}\right)$ and $\left(\sigma_{d}, \varepsilon_{d}\right)$ respectively. Taking the peak stress at the point $\mathrm{D}$ and the strain as reference values, we have

$\zeta_{c}=\sigma_{c} / \sigma_{d}, \quad \lambda_{c}=\varepsilon_{c} / \varepsilon_{d}$

Taking the accumulated number of acoustic emission events $\delta_{z}$ and the time $t_{z}$ at the completion of the experiment as reference values, the accumulated number of $\mathrm{AE}$ events $\delta_{c}$ and the time $t_{c}$ at the point $\mathrm{C}$ are represented as

$\psi_{c}=\delta_{c} / \delta_{z}, \quad \kappa_{c}=t_{c} / t_{z}$

Based on the Weibull distribution (Qin et al., 2006), the probability of destruction $p$ can be represented as

$p=1-e^{-\left(\frac{\varepsilon}{\varepsilon_{0}}\right)^{m}}$

Where $\varepsilon$ is the axial strain in a differential volume; $\varepsilon_{0}$ is the statistical mean of the strain of the differential volume; and $m$ is the shape parameter.

According to (Xue et al., 2014), the probability of threshold destruction $p_{c}$ corresponding to the point $\mathrm{C}$ can be derived, which is represented as

$p_{c}=f_{c}(m)$

Meanwhile, the stress-strain mechanical response of the rock sample can be described by a constitutive formula as follows:

$\sigma=E \varepsilon e^{-\left(\frac{\varepsilon}{\varepsilon_{0}}\right)^{m}}$

Taking the $1^{\text {st }}$ order derivative of $\sigma$ in (4), the peak intensity is derived to be

$\frac{\varepsilon_{d}}{\varepsilon_{0}}=\left(\frac{1}{m}\right)^{\frac{1}{m}}$

From $P^{*}=f(m)$ and Eq.(3), the stress corresponding to the threshold point of destruction $C$ is obtained

$\frac{\varepsilon_{c}}{\varepsilon_{0}}=[-\ln (1-f(m))]^{\frac{1}{m}}$ 

can get

Following Xue (2015), based on Eqs. (5) (7), we

$\zeta_{c}=\frac{\sigma_{c}}{\sigma_{d}}=[-m \ln (1-f(m))]^{\frac{1}{m}}(1-f(m)) e^{\frac{1}{m}}$

One or multiple macroscopic breaking surfaces with sags and crests are usually found on hard and brittle rocks, while acoustic emission occurs in 3D space in the samples. Based on this observation, we believe that the micro-to-macroscopic destruction of rock samples without joint fissure in the laboratory should be developed for 3D, so the threshold probability of destruction under 3D renormalized condition of destruction is computed respectively from Eq. (4). The rock material can be considered as a large system with a large number of micro-blocks, as the result of the complexity of formation environment and long-term geological processes. In this paper, the critical behavior of brittle fracture of the rock material will be studied with the model as shown in Figure 3, which is a 3D lattice renormalization. As shown in Figure 2, a large block is composed of eight small block. Eight large blocks can comprise a larger block, and so on. This is the process of the renormalization theory. For a group containing two blocks which are either broken or unbroken, eight states are possible: $\mathrm{b}_{8} \mathrm{u}_{0}, \mathrm{~b}_{7} \mathrm{u}_{1}, \mathrm{~b}_{6} \mathrm{u}_{2}$, $\mathrm{b}_{5} \mathrm{u}_{3}, \mathrm{~b}_{4} \mathrm{u}_{4}, \mathrm{~b}_{3} \mathrm{u}_{5}, \mathrm{~b}_{2} \mathrm{u}_{6}$, and $\mathrm{b}_{1} \mathrm{u}_{7}$, where the letters " $\mathrm{b}$ ", and " $u$ " represent either a broken block, or an unbroken block. It is obvious to conclude that the failure probability $p_{1}^{(2)}$ of second-order blocks could be expressed as Eq. (9) (Xue, 2011 and Xue et al., 2014)

$$
\begin{gathered}
p_{1}^{(2)}=p_{\mathrm{b}_{8} \mathrm{u}_{0}}+p_{\mathrm{b}_{7} \mathrm{u}_{1}}+p_{\mathrm{b}_{6} \mathrm{u}_{2}}+p_{\mathrm{b}_{5} \mathrm{u}_{3}}+ \\
+p_{\mathrm{b}_{4} \mathrm{u}_{4}}+p_{\mathrm{b}_{3} \mathrm{u}_{5}}+p_{\mathrm{b}_{2} \mathrm{u}_{6}}+p_{\mathrm{b}_{1} \mathrm{u}_{7}}
\end{gathered}
$$

where $p_{1}$ is the failure probability of block. $p^{*}=f(m)$ is illustrated in Figure 3, which shows that the peak strength of rock increases with the decrease in shape parameter, and it can be solved by the method of numerical iteration by substituting Eq. (9) into Eq. (4). The calculated 3D stress level is shown by Figure 4 respectively for $m$ equals 1, 2 3, 4, 5, 6 and 7. The result shown in Figure 5 also indicates that the value of $\zeta_{c}$ also increases with the increase of $m$.

\section{CASE STUDIES}

\section{CASE 1: UNIAXIAL COMPRESSION TEST OF MUD- LIMESTONE SAMPLES}

The mud-limestone samples were obtained from Huaibei, China. Mud-limestone samples with an average density of $2.74 \mathrm{~g} / \mathrm{cm}^{3}$ at room temperature were cut into $\Phi 50 \times 100 \mathrm{~mm}$ cylinders, which were heated up to the designated temperature of $105^{\circ} \mathrm{C}$ in a high-temperature furnace. After the temperature was kept constant for about 24 hours, the furnace was turned off and the specimen was allowed to cool naturally in the furnace. The weight was obtained and the moisture content was calculated. All specimens were subjected to Electro-Hydraulic servo compression testing. AE was simultaneously collected by CTA-1 data acquisition system.

The test result is shown in Figure 5, which is implied that the variation of accumulated AE with stress level can be separated into 3 phases. In the

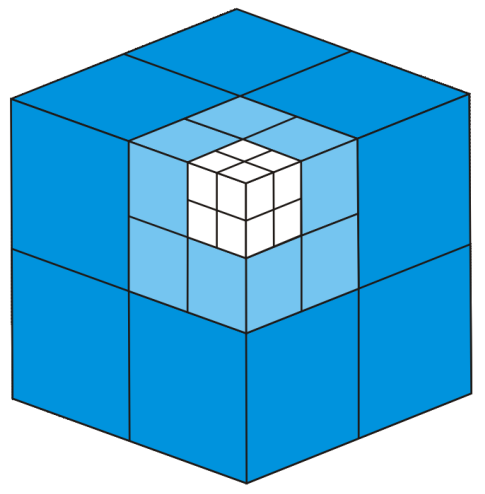

Fig. 2 The 3D renormalization model.

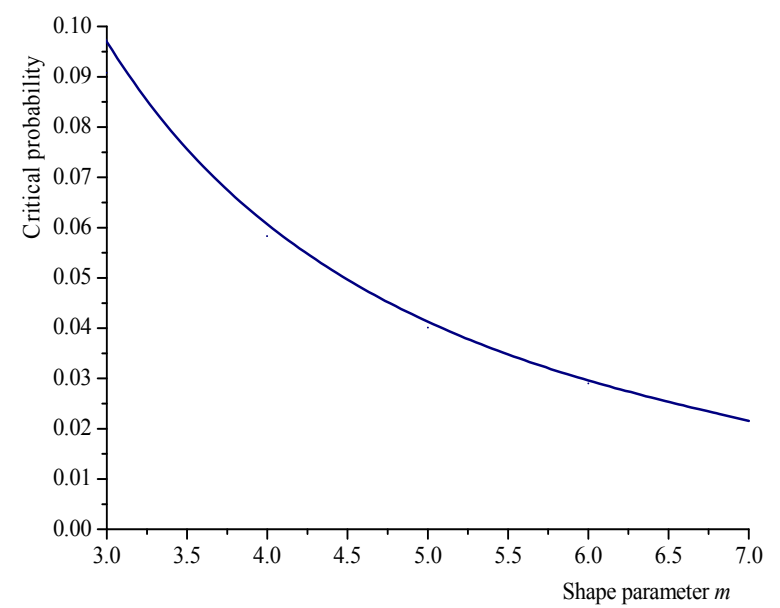

Fig. 3 The variation of the critical failure probability with the shape parameter.

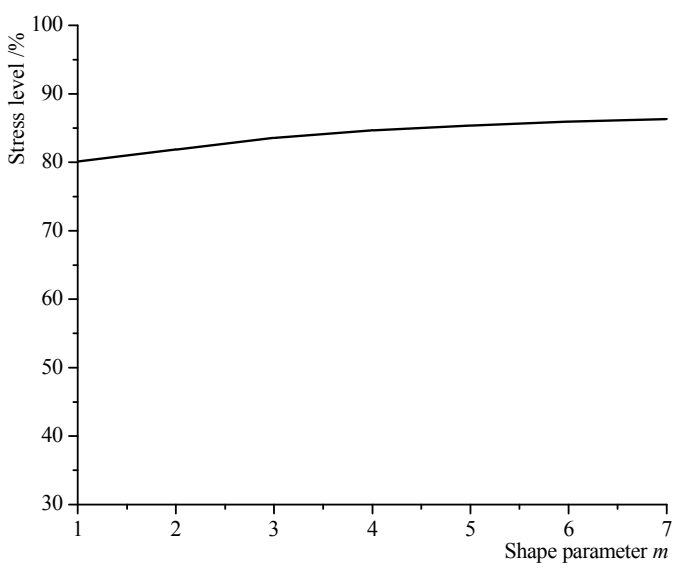

Fig. 4 The variation of the critical stress level with the shape parameter. 


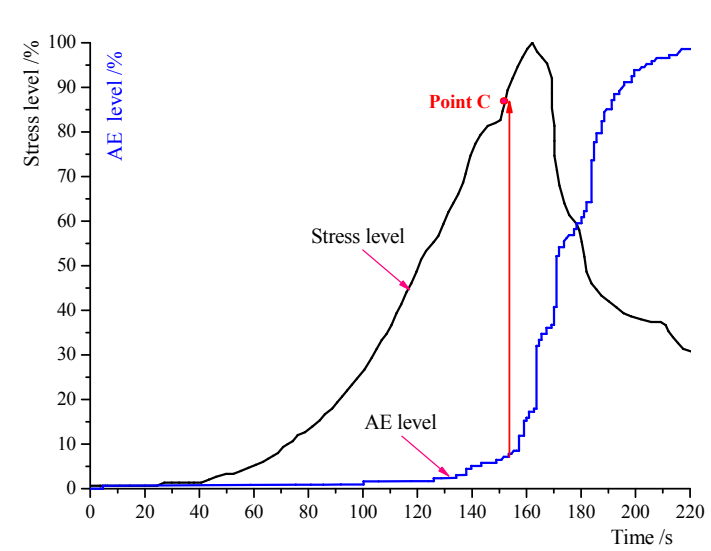

(a)

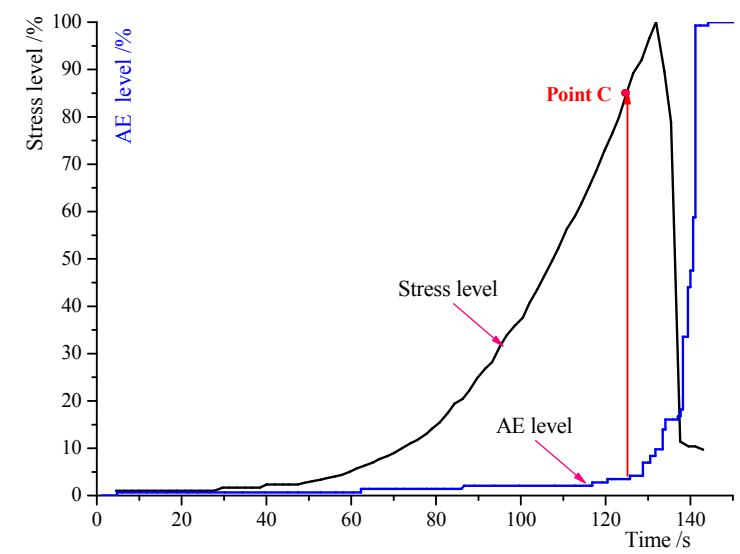

(b)

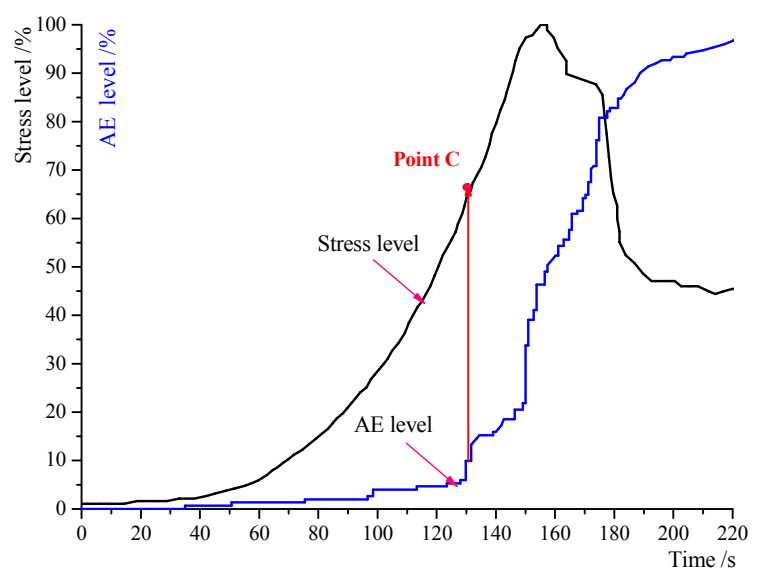

(c)

Fig. 5 Stress-time and AE-time curves of mud limestone.

(a) Dried; (b) Moisture content of $2.90 \%$; (c) Moisture content of $10.21 \%$.

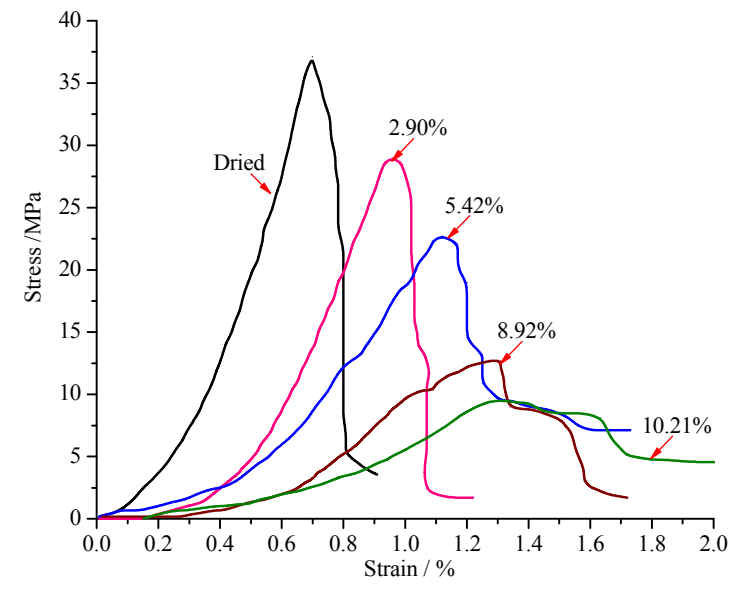

(a)

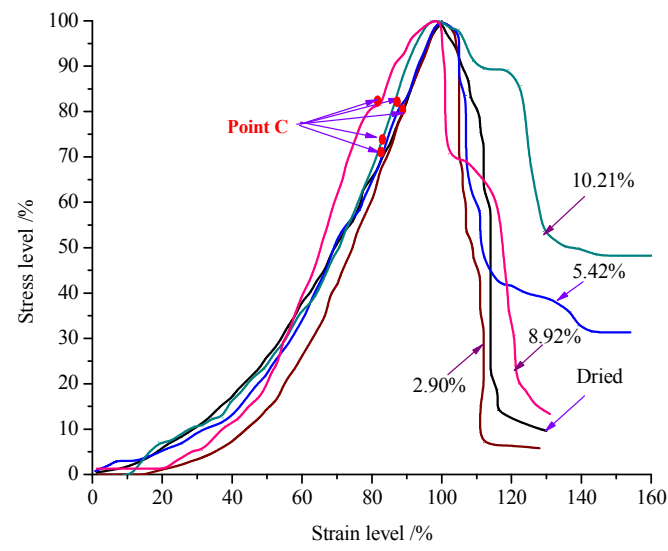

(b)

Fig. 6 Relationship of stress and strain of different moisture content for mud limestone.

(a) Stress vs strain; (b) Normalized stress level vs normalized strain level. 


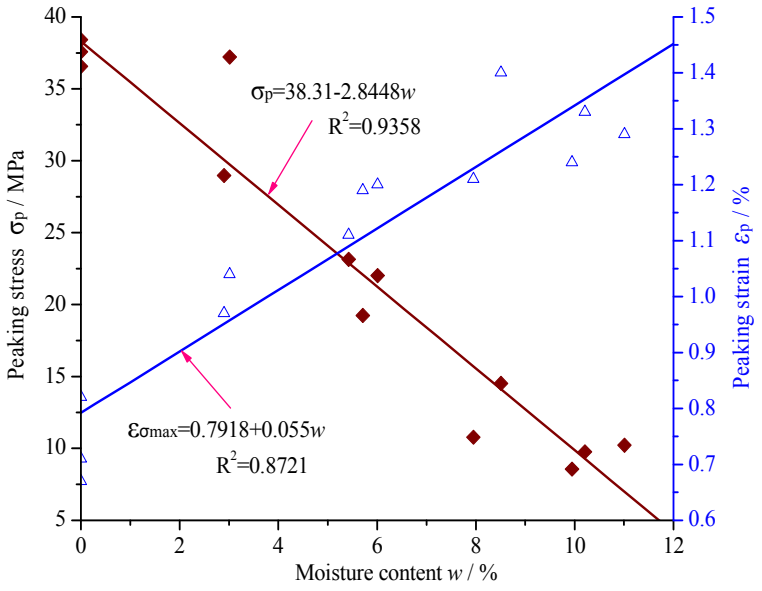

(a)

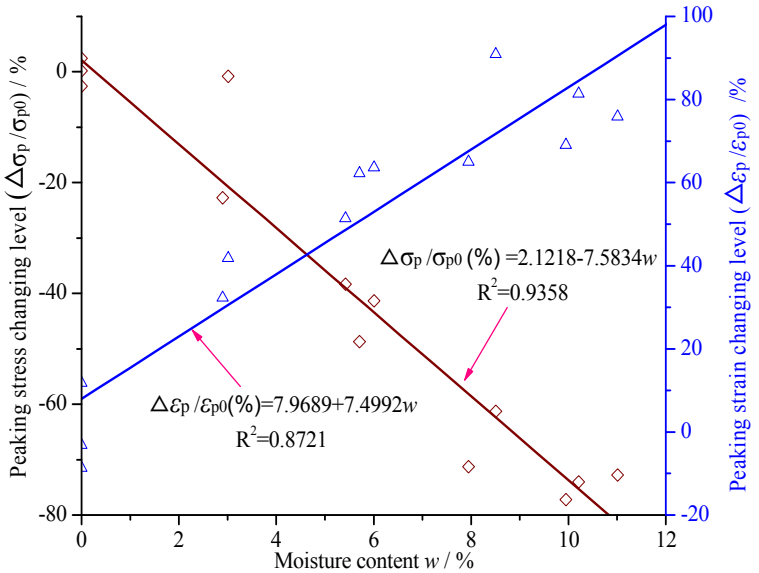

(b)

Fig. 7 Relationship of peak strength, peak strain and moisture kontent.

(a) Peak stress vs. moisture content and peak strain vs. moisture content;

(b) Peak stress changing level vs. moisture content and peak strain changing level vs. moisture content.

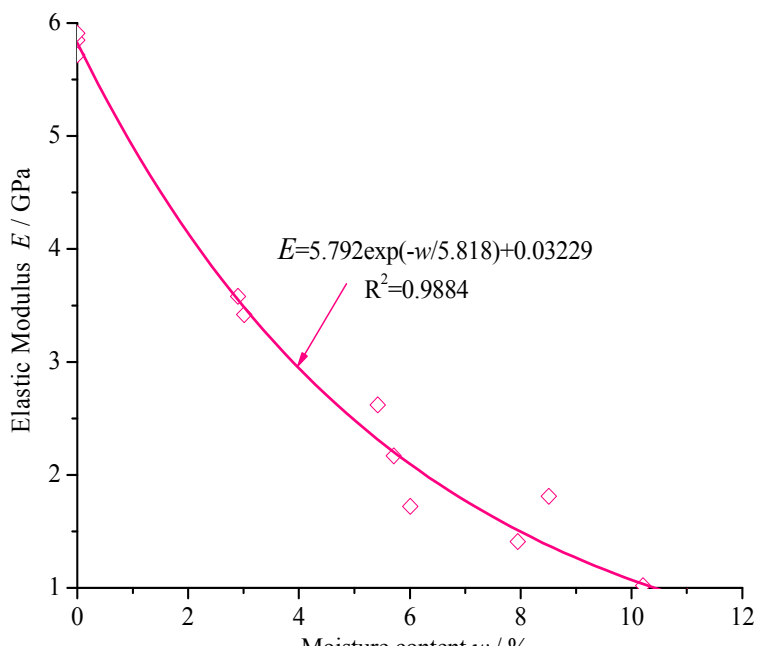

(a)

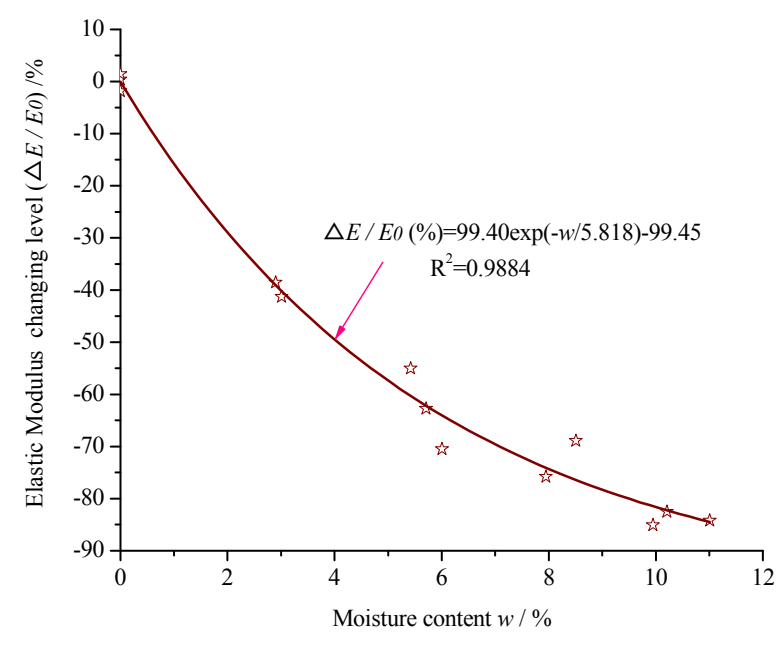

(b)

Fig. 8 Relationship of elastic modulus and moisture content.

(a) Elastic modulus vs. moisture content; (b) Elastic modulus changing level vs. moisture content

compaction and elastic phases, accumulated $\mathrm{AE}$ increases very slowly. Close to Point C (critical stress threshold), many micro cracks form and grow rapidly, and micro breaking is developed spatially in rows along the potential breaking planes until the micro cracks eventually become connected with each other (Fig. 5), as indicated by the localization of strain, and accelerated increase of volumetric strain at the cracks. In this phase, the accumulated AE quickly increases. The average value of stress level for point $\mathrm{C}$ is 71 to $86 \%$, as calculated from Figure 5. It also suggests that the variation of AE can reflect the changes of stress state, which may provide very useful information on rock stability.
Figure 5 (d), Figure 6 and Figure 7 show that the total number of accumulated AE, elastic modulus and peak stress are decreasing with the increase of moisture content, but the peak strain is linearly increasing. Therefore, the plasticity of mud-limestone is increasing with the increase of moisture content. Comparing Figure 5 (d) with Figure 6 (a), it shows clearly that with higher moisture content in mudlimestone, the strength of the samples and the number of $\mathrm{AE}$ events decrease, but it shows little influence on the stress level at the threshold point $\mathrm{C}$ (as shown by Figure 6 (b)). 


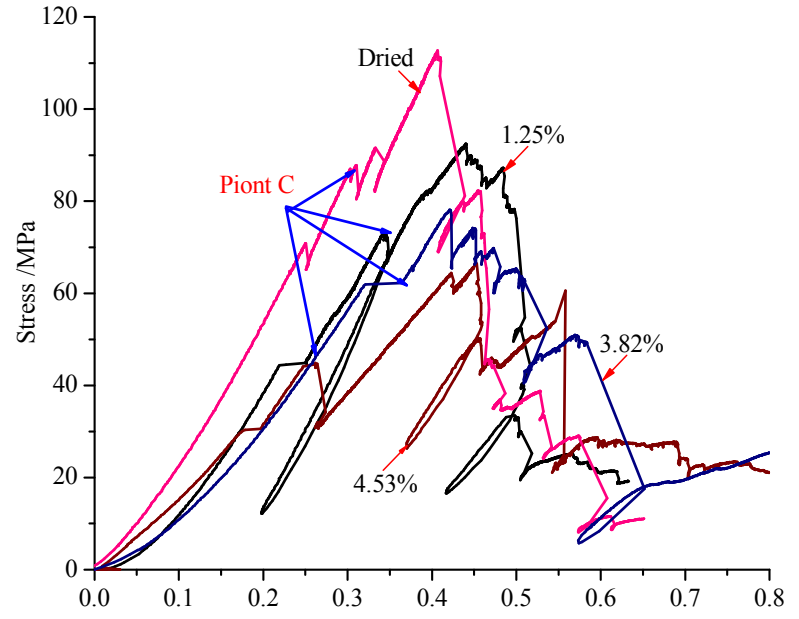

(a)

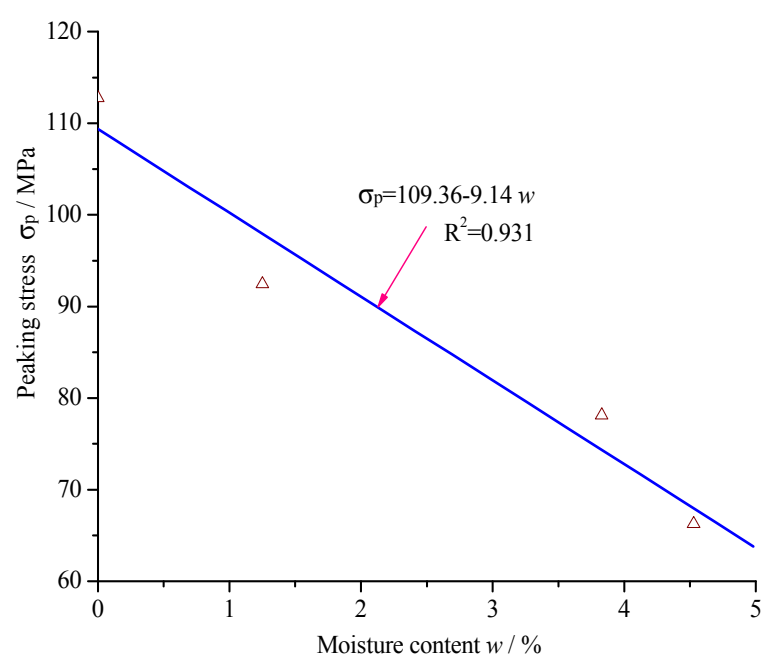

(b)

Fig. 9 Relationship of stress, strain, peak stress and moisture content.

(a) Stress vs. strain under different moisture content; (b) Peak stress vs. moisture content.

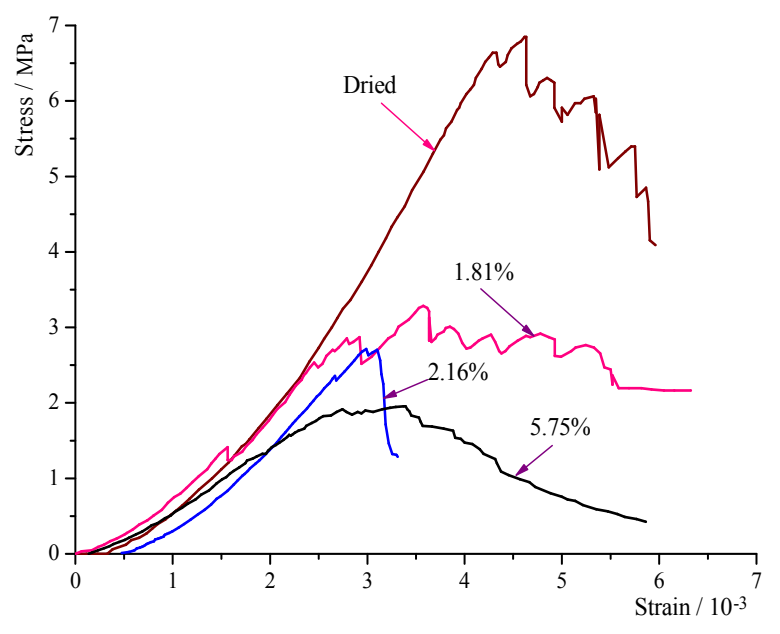

(a)

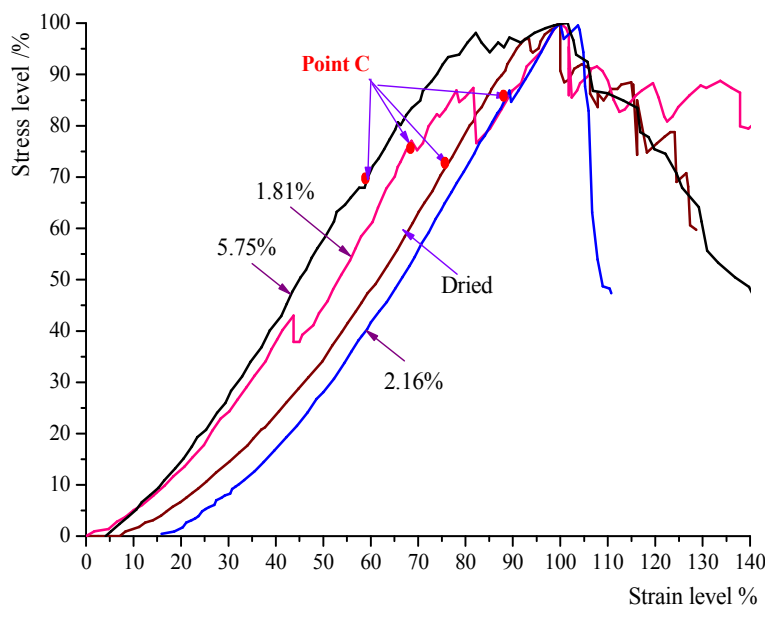

(b)

Fig. 10 Stress-strain curves of coal or rock with different moisture contents.

(a) The curve of stress and strain; (b) Stress level vs. Strain level.

\section{CASE 2: UNIAXIAL COMPRESSION TEST OF SANSTONE SAMPLES}

The sandstone samples were obtained from Linyi, China. The samples with an average density of $2.42 \mathrm{~g} / \mathrm{cm}^{3}$ at room temperature were cut into $\Phi 50 \times 100 \mathrm{~mm}$ cylinders, which were then heated up to the designated temperature of $105{ }^{\circ} \mathrm{C}$ in a hightemperature furnace (type MTS652.02). After the temperature was kept constant for about 4 hours, the furnace was turned off and the specimens were allowed to cool in the furnace. The samples were flooded, and the moisture content was determined. All specimens were subjected to Electro-Hydraulic servo compression testing. The test result in Figure 9 shows that with the increase of moisture content, the peak strength linearly decreases, and when the ratio of loading stress to peak stress varies from 65 to $85 \%$, the rocks begin to yield

\section{CASE 3: UNIAXIAL COMPRESSION TEST OF COAL ROCK SAMPLES}

The coal rock samples were obtained from Jincheng, China. The samples were cut into hexahedron specimens with dimensions of $20 \times 20 \times 140 \mathrm{~mm}^{3}$, and placed in a furnace to dry. After the samples were flooded, the moisture contents were determined. All specimens were analyzed on Electro-Hydraulic servo compression testing system (AG-250kN). AE was simultaneously collected by PCI-2 data acquisition system (Qin et al., 2012).

Results in Figure 10 and Figure 11 show that the peak strength exhibits a negative exponential decrease with the increase of moisture content, and when the ratio of loading stress to peak stress is from 70 to $85 \%$, the rocks begin to yield. Figure $11 \mathrm{a}$ and Figure 10b indicate that higher moisture content would change the inner structure state and mechanical 


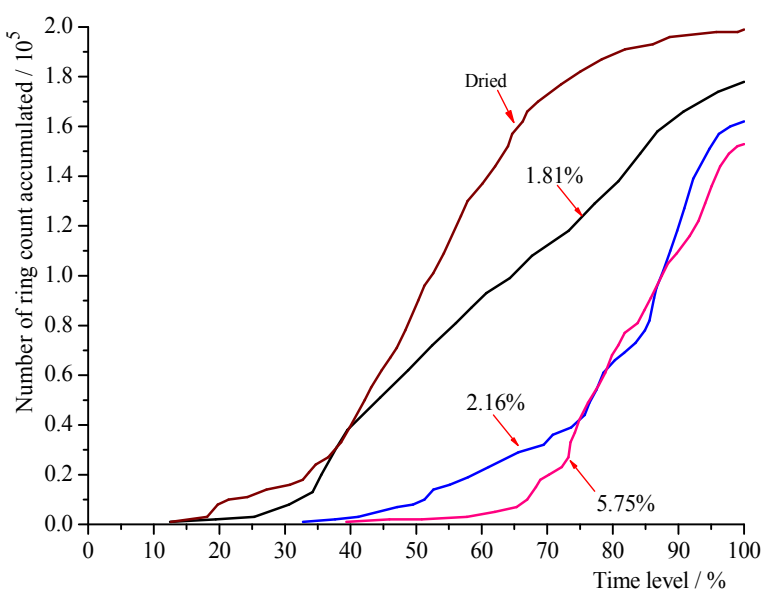

(a)

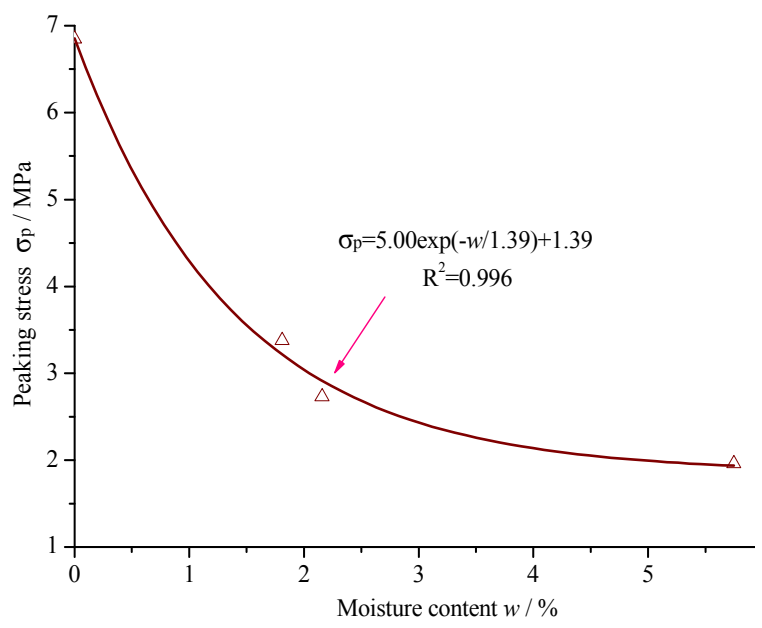

(b)

Fig. 11 Relationship of AE, time level, peak stress and moisture content.

(a) Number of ring counts vs. time level for different moisture content; (b) Peak stress vs. moisture content

properties of the rocks, decrease the strength of the samples and the number of AE events, and reduce the energy released from the destruction process, but it has little influence on the stress level at the threshold point C.

\section{CASE 4: UNIAXIAL COMPRESSION TEST OF SANDSTONE SAMPLES}

The sandstone samples in this test were obtained from Chongqing, China, Sandstone samples with an average density of $2.31 \mathrm{~g} / \mathrm{cm}^{3}$ at room temperature were cut into $\Phi 50 \times 100 \mathrm{~mm}$ cylinders. The samples were heated up to the designated temperature of $105^{\circ} \mathrm{C}$ to dry. After the temperature was kept constant for about 48 hours (Li, 2012.), the furnace was turned off and the specimens were allowed to cool down in the furnace. Additionally, the naturally dried samples were placed in good ventilated location for 2 weeks. The saturated samples were boiled in water for 8 hours, and the moisture contents were determined. All specimens were analyzed on Electro-Hydraulic servo compression testing system (MTS815). AE was simultaneously collected by PCI-2 data acquisition system. The result shown in Figure 12 indicates that the total number of accumulated AE decreases with the increase of moisture content. The results obtained with these four different types of rocks clearly demonstrate that the increased moisture content changes the inner structure and mechanical properties of the rocks, and decreases the strength of the sample and the occurrence of acoustic emission, resulting in less energy being released during the destruction of the samples. Consequently, the rapid release of the accumulated energy causes fewer hazards. However, the variation of moisture content has little influence on the stress level at the threshold point $\mathrm{C}$, the stress level which is from 70 to $80 \%$.
Specifically, because of the influence of test conditions and rock properties, and the principle of choosing points of sharp change, the data at the threshold point may have some errors, which will be continuously improved in future investigation. For example, inevitable damage during sample preparation could make cracks in the samples, which may lead to local stress concentration and greatly affect the behavior of AE by moving the characteristic point of $\mathrm{AE}$ to an earlier time.

\section{CONCLUSIONS}

Using fracture mechanics and statistical physics as key tools to study crack damage in rocks, the stress at the critical point on the stress-strain curve is found to be correlated with the point of rapid increase on the total number of accumulated AE - strain (or stress) curve. We can use the variation of rock $\mathrm{AE}$ to obtain the end stress of rock elastic stage and Poisson's ratio. In addition, the stress ratio at the critical point could be described by mathematical expressions, which could be reasonably proved by experimental results. We emphasize that this estimation procedure explicitly recognizes the stress level and evolution of the total number of accumulated AE-stress field.

However, the complexity of rock structure may lead to scattered data during experiments, so the interferences introduced by individual difference among the samples cannot be excluded. Therefore, these conclusions need more experiments for validation, and further investigation on their robustness under various conditions. In the longterm, physical predicating methods can be developed for recognizing the threshold information of destruction, promoting the interaction and incorporation of experimental science, rock mechanics, geophysics, and other subjects. 


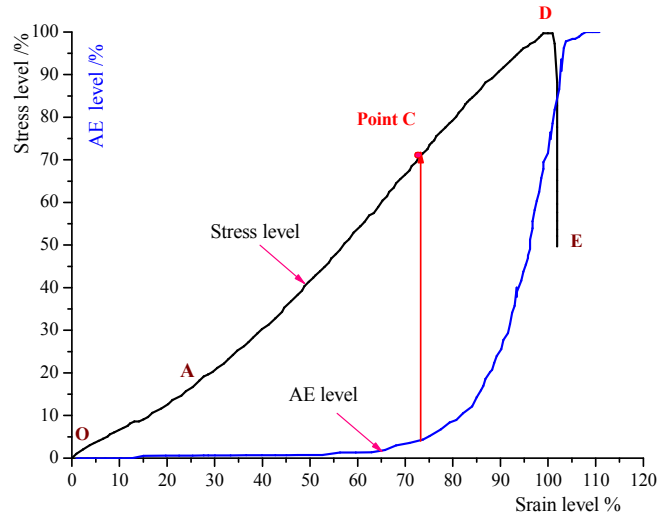

(a)

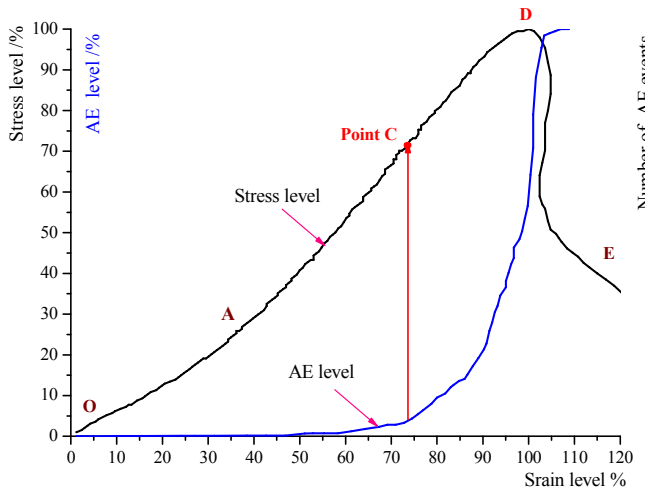

(c)

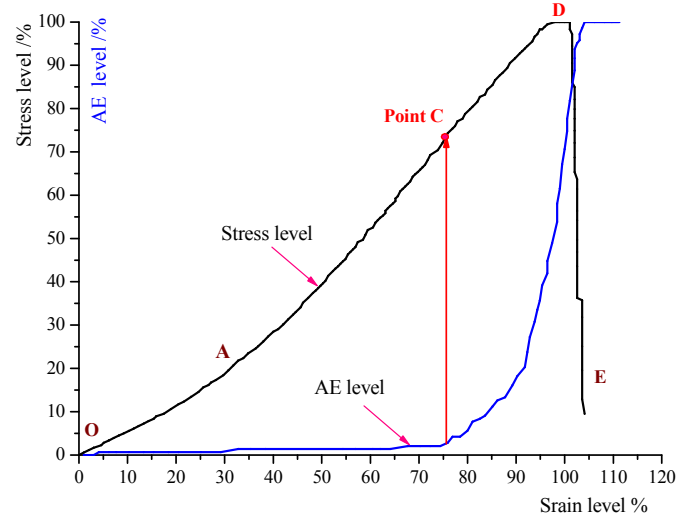

(b)

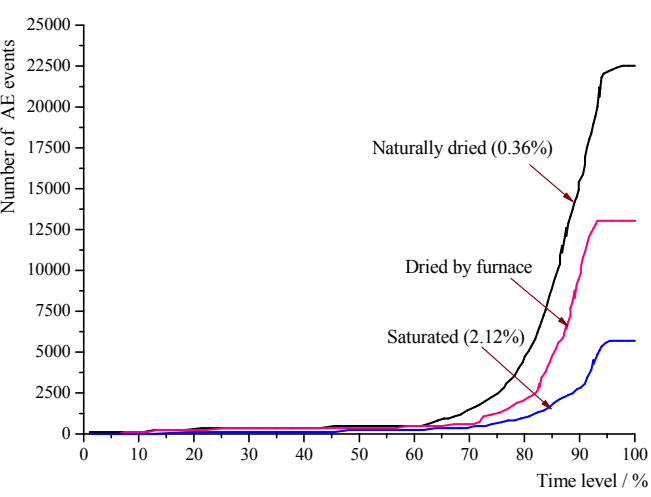

(d)

Fig. 12 Relationship between parameters of sandstone stress, strain, and AE under different moisture content. (a) Naturally dried (Moisture content of $0.36 \%$ ); (b) Dried by furnace; (c) Saturated (Moisture content of $2.12 \%$ ); (d) AE-time curves of sandstone with different moisture contents.

\section{ACKNOWLEDGEMENTS}

This research was supported by the State Basic Research and Development Program of China (No. 2013CB036003), the Priority Academic Program Development of Jiangsu Higher Education Institutions, Transport project (2013318J12330) and the National Natural Science Foundation of China (Grant No.41102201, No.41302233).

\section{REFERENCES}

Butt, S.D., Mukherjee, C. and Lebans, G.: 2000, Evaluation of acoustic attenuation as an indicator of roof stability in advancing headings. International Journal of Rock Mechanics and Mining Sciences, 37, No. 7, 11231131. DOI:10.1016/S1365-1609(00)00048-4

Brace, W.F., Paulding, B.W. and Scholz, C.: 1966, Dilatancy in the fracture of crystalline rocks. Journal of Geophysical Research, 71, No. 16, 3939-3953. DOI: 10.1029/JZ071i016p03939

Cai, M., Kaiser, P.K. and Martin, C.D.: 1998, A tensile model for the interpretation of microseismic events near underground openings. Pure and Applied Geophysiics, 153, No. 1, 67-92. DOI: $10.1007 / \mathrm{s} 000240050185$

Cai, M., Kaiser, P.K, Tasaka, Y., Maejima, T., Morioka, H. and Minami, M.: 2004, Generalized crack initiation and crack damage stress thresholds of brittle rock masses near underground excavations. International Journal of Rock Mechanics and Mining Sciences, 41, No. 5, 833-847.

DOI:10.1016/j.ijrmms.2004.02.001

Dai, S.T. and Labuz, J.F.: 2005, Damage and failure analysis of brittle materials by acoustic emission. Rock Mechanics and Rock Engineering, 38, No. 1, 119. DOI: $10.1007 / \mathrm{s} 00603-004-0031-6$

Fonseka, G.M., Murrell, S.A.F. and Barnes, P.: 1985, Scanning electron microscope and acoustic emission studies of crack development in rocks. International Journal of Rock Mechanics and Mining Sciences \& Geomechanics Abstracts, 22, No. 5, 273-289. DOI: $10.1016 / 0148-9062(85) 92060-1$

Ganne, P., Vervoort, A. and Wevers, M.: 2007, Quantification of pre-break brittle damage correlation between acoustic emission and observed microfracture. International Journal of Rock Mechanics and Mining Sciences, 44, No. 5, 720-729.

DOI: $10.1016 /$ j.ijrmms.2006.11.003

Holcomb, D.J.: 1993, General theory of Kaiser Effect. International Journal of Rock Mechanics and Mining Sciences \& Geomechanics Abstracts, 30, No. 7, 929935. DOI: 10.1016/0148-9062(93)90047-H

Kramadibrata, S., Simangunsong, G.M., Matsui, K. and Shimada, H.: 2011, Role of acoustic emission for solving rock engineering problems in Indonesian underground mining. Rock Mechanics and Rock 
Engineering, 44, No. 3, 281-289.

DOI: $10.1007 / \mathrm{s} 00603-010-0125-2$

Lamagnère, L., Carmona, F. and Sornette, D.: 1996, Experimental realisation of critical thermal fuse rupture. Physical Review Letters, 77, No. 13, 27382741. DOI: 10.1103/PhysRevLett.77.2738

Lavrov, A.: 2003, The Kaiser effect in rocks: principles and stress emtimation techniques. International Journal of Rock Mechanics and Mining Sciences, 40, No. 2, 151-171. DOI: 10.1016/S1365-1609(02)00138-7

Li, S.C.: 2008, Deformation and damage law and its nonlinear characteristics of rock under cyclic load. Chongqing: Ph.D. Thesis, Chongqing University.

Li, S.L., Yin, X.G., Wang., Y.J. and Tang, H.Y.: 2004, Study on acoustic emission characteristics of uniaxial compressive rock failure. Chinese Journal of Rock Mechanics and Engineering, 23, No. 5, 2499-2503, (in Chinese). DOI: $10.3321 /$ j.issn:1000-6915.2004.15.003

Lockner, D.A., Byerlee, J.D., Kuksenko, V., Ponomarev, A. and Sirotin, A. :1992, Observation of quasi-static fault growth from acoustic emissions. In: Evans B, Wong T.-F, editors. Fault mechanics and transport properties of rocks. New York, Academic press, 3-31.

Martin, C.D., and Chandler, N.A.: 1994, The progressive fracture of $\mathrm{Lac} \mathrm{du}$ Bonnet granite. International Journal of Rock Mechanics and Mining Sciences, 31, No. 6, 643-659. DOI: 10.1016/0148-9062(94)90005-1

Martin, C.D., Christiansson, R., and Söderhäll, J.: 2001, Rock stability considerations for siting and constructing a KBS-3 repository. Based on Experiences from Äspö HRL, AECL's URL, Tunneling and Mining.

Pan, L.Y. and Yang, H.Z.: 2004, Dilatancy theory for identification of premonitory information of rock burst (in Chinese). Chinese Journal of Rock Mechanics and Engineering, 23, No. sup1, 4528-4530. DOI: $10.3321 /$ j.issn:1000-6915.2004.z1.056

Qin, H., Huang, G. and Wang, W.Z.: 2012, Experimental study of acoustic emission characteristcis of coal samples with different moisture contents in process of compression deformation and failure (in Chinese). Chinese Journal of Rock Mechanics and Engineering, 31, No. 6, 1115-1120.

DOI: 10.3969/j.issn.1000-6915.2012.06.004

Qin, S.Q., Jiao, J.J. and Li, Z.G.: 2006, Nonlinear evolutionary mechanisms of instability of plane-shear slope: catastrophe, bifurcation, chaos and physical prediction. Rock Mechanics and Rock Engineering, 31, No. 1, 59-76. DOI: 10.1007/s00603-005-0049-4
Rudajev, V., Vilhelm, J., Kozák, J. and Lokajíček, T.: 1996, Statistical precursors of instability of loaded rock samples based on acoustic emission. International Journal of Rock Mechanics and Mining Sciences \& Geomechanics Abstracts, 33, No. 7, 743-748. DOI: 10.1016/0148-9062(96)00023-X

Sornette, D. and Andersen, J.V.: 1998, Scaling with respect to disorder in time- to-failure. The European Physical Journal B, 1, No. 3, 353-357.

DOI: $10.1007 / \mathrm{s} 100510050194$

Sornette, D.: 1998, Discrete scale invariance and complex dimensions. Physics Reports, 29, No. 7, 239-270. DOI: 10.1016/S0370-1573(97)00076-8

Sun, Q. and Zhu, S.Y.: 2014, Wave velocity and stress/strain in rock brittle failure. Environmental Earth Sciences, 72, No. 3, 861-886.

DOI: $10.1007 / \mathrm{s} 12665-013-3009-4$

Tan, Y.L., Li, F.C., Zhou, H., and Han, X.J. : 2000, Analysis on acoustic emission pattern for rock burst (in Chinese). Chinese Journal of Rock Mechanics and Engineering, 19, No. 4, 425-428.

DOI: 10.3321/j.issn:1000-6915.2000.04.006

Xu, J., Wu, H., Lu, L.F., Yang, H.W. and Tan, H.Y.: 2012, Experimental study of acoustic emission characteristcis during shearing process of sandstone under different water contents (in Chinese). Chinese Journal of Rock Mechanics and Engineering, 31, No. 5, 914-920. DOI: 10.3969/j.issn.1000-6915.2012.05.007

Xue, L.: 2011, Renormalization Study on Rock Failure and Its Application to Strong Earthquake Prediction (in Chinese). Beijing: Ph.D. Thesis, Institute of Geology and Geophysics Chinese Academy of Sciences.

Xue, L.: 2015, A potential stress indicator for failure prediction of laboratory-scale rock samples. Arabian Journal of Geosciences, 8, No. 6, 3441-3449. DOI:10.1007/s12517-014-1456-1

Xue, L., Qi, M., Qin, S.Q., Li, G.L., Li, P. and Wang, M.M.: 2014, A Potential Strain Indicator for Brittle Failure Prediction of Low-Porosity Rock: Part II-Theoretical Studies Based on Renormalization Group Theory. Rock Mechanics and Rock Engineering (Online). DOI:10.1007/s00603-014-0675-9

Yang, M., Manabe, K., Hayashi, K., Miyazaki, M. and Aikawa, N.: 2003, Data fusion of distributed AE sensors for the detection of friction sources during press forming. Journal of Materials Processing Technology , 139, 368-372. DOI: $10.1016 / \mathrm{S} 0924-0136(03) 00533-8$ 